\title{
Commentary: A "shoot first (with anti-psychotics) and ask questions later" approach is not appropriate for the management of delirium after cardiac surgery
}

One of the earlier reports of delirium following cardiac surgery was described in 1964 by Blachy and Starr ${ }^{1}$ entitled "Post-Cardiotomy Delirium." Now, delirium remains an important modifier of short- and long-term outcomes in at least 1 in 5 patients after cardiac surgery. ${ }^{2}$ Still, the mechanisms that underlie this syndrome are relatively poorly understood. Among the many prevailing theories that subtend the onset of delirium are derangements of neurotransmitter systems within the brain. ${ }^{3}$ Antipsychotics are therefore an attractive class of pharmacologic agents to mitigate the incidence and duration of delirium in the intensive care unit. The MIND-USA trial by Girard and colleagues ${ }^{4}$ is the most recent trial to examine the use of antipsychotic agents for this purpose (see also the Effect of Intravenous Haloperidol on the Duration of Delirium and Coma in Critically Ill Patients [HOPE-ICU] $]^{3}$ and The Prophylactic Haloperidol Use for Delirium in Intensive Care Unit Patients at High Risk for Delirium [REDUCE] ${ }^{5}$ trials).

The editorial in this issue of the Journal by Cha and Brown $^{6}$ is an excellent overview of the relevance of the The Modifying the Impact of Intensive Care Unit-Associated Neurological Dysfunction-USA (MIND-USA) trial to the postoperative cardiac surgical patient. First, antipsychotic medications reduce neither delirium-free, coma-free days nor 90-day mortality risk, specifically in hypoactive delirium, which is highly prevalent among cardiac surgical patients. ${ }^{7}$ By way of analogy, just as the use of furosemide does not treat acute kidney injury, the use of haloperidol or ziprasidone does not "fix" delirium. Nonetheless, despite published guidelines, the use of antipsychotic medications remains in cardiac surgery. ${ }^{8}$ Second, best practices with the intensive care unit liberation needed.

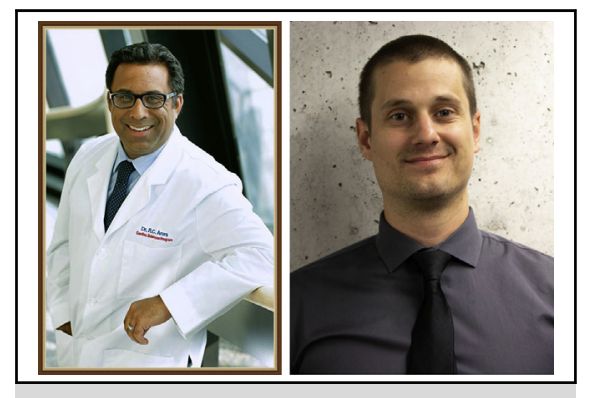

Rakesh C. Arora, MD, PhD, FRCSC, FACS (left), and Dustin Scott Kehler, MSc, PhD (right)

Central Message

The perioperative team needs to identify and treat the mechanism of delirium, not just treat the symptoms with antipsychotic medications.

See Article page 1895.

bundle (ie, "ABCDE[F]" bundle) was a key element in caring for patients enrolled in the MIND-USA study (see also Ali and colleagues ${ }^{9}$ and Engelman and associates ${ }^{10}$ ). Third, Cha and Brown ${ }^{6}$ emphasize as essential an understanding of modifiable risk factors (ie, the potential mechanism) that contribute to the onset of postoperative delirium. The idea of "shooting first" with antipsychotics and then searching for reasons why hypoactive delirium has occurred thus can no longer be considered best practice. Here, we agree that regular systematic screening to mitigate modifiable delirium risk factors is

The use of tools at the bedside that are capable of identifying the spectrum of delirium presentation, from hypoactive to hyperactive delirium, needs to be emphasized. Although the Society of Thoracic Surgeons Adult Cardiac Surgery Database does capture rates of delirium, it is limited by its definition of the hyperactive form ("marked by an acute course of illness, confusion, and cerebral excitement"). Arenson and colleagues ${ }^{11}$ have demonstrated that implementing a systematic delirium screening tool in the cardiovascular intensive care unit (such as the Confusion Assessment Method for the ICU [CAM-ICU] used in the MIND-USA trial) resulted in a significant increase in postoperative delirium after cardiac surgery. As such, the potential underdiagnosis of delirium by the Society of Thoracic 
Surgeons Adult Cardiac Surgery Database definition may result in under recognition of end-organ brain dysfunction diagnosis in postoperative cardiac surgical patients. The ability of a systematic screening tool to improve risk prediction of poor outcomes after cardiac surgery, however, requires further study. Whether the institution of an interdisciplinary, multicomponent, nonpharmacologic program will mitigate delirium and its associated risks is a motivating area of inquiry.

\section{References}

1. Blachy PH, Starr A. Post-cardiotomy delirium. Am J Psychiatry. 1964;121: $371-5$.

2. Arora RC, Djaiani G, Rudolph JL. Detection, prevention, and management of delirium in the critically ill cardiac patient and patients who undergo cardiac procedures. Can J Cardiol. 2017;33:80-7.

3. Page VJ, Ely EW, Gates S, Zhao XB, Alce T, Shintani A, et al. Effect of intravenous haloperidol on the duration of delirium and coma in critically ill patients (Hope-ICU): a randomised, double-blind, placebo-controlled trial. Lancet Respir Med. 2013;1:515-23.
4. Girard TD, Exline MC, Carson SS, Hough CL, Rock P, Gong MN, et al; MINDUSA Investigators. Haloperidol and ziprasidone for treatment of delirium in critical illness. N Engl J Med. 2018;379:2506-16.

5. van den Boogaard $M$, Slooter AJ, Brüggemann RJ, Schoonhoven L, Beishuizen A, Vermeijden JW, et al. Effect of haloperidol on survival among critically ill adults with a high risk of delirium: the REDUCE randomized clinical trial. JAMA. 2018;319:680-90

6. Cha S, Brown CH IV. Treating delirium in the intensive care unit: no easy answers. J Thorac Cardiovasc Surg. 2020;159:1895-8.

7. McPherson JA, Wagner CE, Boehm LM, Hall JD, Johnson DC, Miller LR, et al Delirium in the cardiovascular ICU: exploring modifiable risk factors. Crit Care Med. 2013;41:405-13.

8. Kim DH, Mahesri M, Bateman BT, Huybrechts KF, Inouye SK, Marcantonio ER, et al. Longitudinal trends and variation in antipsychotic use in older adults after cardiac surgery. J Am Geriatr Soc. 2018:66:1491-8.

9. Ali AA, White P, Xiang B, Lin HY, Tsui SS, Ashley E, et al. Hearts from DCD donors display acceptable biventricular function after heart transplantation in pigs. Am J Transplant. 2011;11:1621-32.

10. Engelman DT, Ben Ali W, Williams JB, Perrault LP, Reddy VS, Arora RC, et al Guidelines for perioperative care in cardiac surgery: enhanced recovery after surgery society recommendations. JAMA Surg. 2019;12:E1-12.

11. Arenson BG, MacDonald LA, Grocott HP, Hiebert BM, Arora RC. Effect of intensive care unit environment on in-hospital delirium after cardiac surgery. $J$ Thorac Cardiovasc Surg. 2013;146:172-8. 